\title{
Expectativas promissoras: comércio e perspectivas de cooperação bilateral nas relações Brasil-União Soviética (1964-1967)
}

\author{
Promising Expectations: \\ trade and perspectives of bilateral cooperation \\ between Brazil and the Soviet Union (1964-1967)
}

DOI: $10.21530 /$ ci.v13n2.2018.773

Gianfranco Caterina ${ }^{1}$

\section{Resumo}

Este artigo busca compreender a dinâmica das relações entre Brasil e União Soviética logo após o golpe civil-militar de 1964. Apesar da retórica anticomunista, das arbitrariedades e perseguições a elementos considerados subversivos e comunistas brasileiros, o regime que se instalou após a tomada de poder em abril de 1964 permanecia interessado na manutenção de boas relações com a superpotência euroasiática. Argumenta-se que o comércio teve papel relevante nesse período, levando à busca por uma institucionalização das relações interestatais, visando a retomada das conversações acerca de assistência soviética a grandes projetos de infraestrutura no país. Dentro dessa chave de entendimento, a URSS poderia desempenhar um papel relevante na industrialização do Brasil. Em 1967, o Brasil retomava o posto de principal parceiro comercial da URSS na América Latina (excetuando-se Cuba). No entanto, as cifras eram inferiores em comparação às trocas no biênio 1962-63. Este artigo busca evidenciar como esforços de reaproximação foram importantes para moldar ações de cooperação econômica e estratégica posteriores entre os dois países.

Palavras-chave: Política Externa Brasileira; União Soviética; Regime Militar; Cooperação Econômica.

1 Doutorando em História, Política e Bens Culturais no CPDOC/FGV no Rio de Janeiro. É mestre em História Social pela PUC-SP (2012) e especialista em Economia pela EESP-FGV (2014). Em 2016, foi pesquisador visitante na George Washington University em Washington, DC.

Artigo submetido em 06/03/2018 e aprovado em 06/09/2018. 


\begin{abstract}
This article assesses the relationship between the governments of Brazil and the Soviet Union after the 1964 civil-military coup. Despite the anti-Communist rhetoric, arbitrariness and persecutions of so-called subversive elements and Brazilian communists, the regime that gained power in April 1964 was still interested in maintaining good relations with the USSR. We argue that trade played an important role during this period; it fostered an institutionalization of inter-state relations, which in turn led to the resumption of conversations about Soviet assistance for big infrastructure projects in Brazil. Within this framework, the USSR would be able to play a relevant role in Brazil's industrialization. In 1967, Brazil regained the position of the most important Soviet trade partner in Latin America (except for Cuba). However, the figures were still smaller than those for bilateral trade in 1962-63. This paper seeks to explain how rapprochement efforts were important for promoting later strategic and economic cooperation between the two countries.
\end{abstract}

Keywords: Brazilian Foreign Policy; Soviet Union; Military Regime; Economic Cooperation.

\title{
Introdução ${ }^{2}$
}

A normalização das relações diplomáticas entre Brasil e União Soviética, iniciada ao final da Segunda Guerra Mundial, durou apenas dois anos e meio. Em outubro de 1947, o governo Dutra rompeu relações com a URSS, gerando um distanciamento que perdurou por algum tempo. Seria somente em dezembro de 1959 que o presidente Kubitschek enviaria uma missão a Moscou para a assinatura de um acordo comercial bilateral. Em 1961, aconteceria a abertura de respectivos escritórios comerciais e o reestabelecimento de relações diplomáticas entre os dois países (VOLCHEK, 1985).

Sabe-se, no entanto, que uma das justificativas oficiais para a intervenção militar em 1964 foi o temor, de parte das elites civil e militar do País, que o Brasil enveredasse para uma trajetória de cunho socialista. Esses grupos nutriam também uma enorme desconfiança do presidente João Goulart. Com isso em mente, este artigo buscará responder à seguinte pergunta: como os esforços de reaproximação entre o Brasil e a URSS, após o golpe civil-militar de 1964, foram importantes para modelar ações de cooperação econômica bilateral que ocorreriam posteriormente?

O primeiro passo para responder a essa questão de forma satisfatória é uma discussão bibliográfica bem fundamentada. É consenso na literatura sublinhar a

\footnotetext{
2 Agradeço ao professor Alexandre Moreli por seus comentários e sugestões.
} 
singularidade das relações diplomáticas entre Brasil e União Soviética logo após o golpe civil-militar de 1964. Vizentini argumenta que a retórica típica da Guerra Fria e das fronteiras ideológicas "não correspondeu plenamente à prática" nas interações com a superpotência euroasiática. Segundo ele, a manutenção de laços diplomáticos plenos com a URSS e com os países de seu bloco derivavam de "necessidades comerciais", além do fato de que a atuação internacional soviética se pautava por uma "diplomacia tradicional e legalista, e não revolucionária como a de Cuba e da China” (VIZENTINI, 1998, p. 61).

Essa tendência se acentuaria ao longo dos anos de 1960. A União Soviética, após o cisma com a República Popular da China e dificuldades em sua parceria com Cuba, estava mais interessada na manutenção do status quo global e preocupada com sua própria conjuntura doméstica do que com a difusão revolucionária do comunismo, especialmente após a ascensão de Leonid Brejnev como secretáriogeral do Partido Comunista da União Soviética (PCUS), em outubro de 1964. Daí se deduz uma das razões que indicam por que o Brasil rompeu relações diplomáticas com Cuba logo após o golpe de 1964, mas não o fez com a URSS - além dos conhecidos interesses comerciais e econômicos envolvidos ${ }^{3}$.

De forma análoga a Vizentini, Cervo situa as relações brasileiro-soviéticas dentro de um "universalismo inevitável" durante o governo Castello Branco. Ele sublinha que o governo brasileiro tinha a "intenção" de que as relações "puramente comerciais” passassem ao estágio de relações econômicas, nas quais "se agregassem componentes de desenvolvimento, como importação de máquinas, equipamentos e tecnologias" (CERVO; BUENO, 2008, p. 377-379). Ou seja, a superpotência socialista poderia exercer um papel relevante no esforço de industrialização do Brasil.

Argumentamos, dessa forma, que a manutenção das relações bilaterais procede desses três pontos: o fato de o anticomunismo da cúpula militar brasileira estar concentrado em Cuba e não na URSS, mudanças domésticas importantes em curso na superpotência socialista, e a possibilidade de a mesma exercer um papel importante na industrialização do Brasil. Assim, o interesse brasileiro iria além da mera expansão comercial apontada por outros dois autores como fator principal de aglutinação entre os dois países (SILVA, 2014; BARRETO FILHO, 2006). André Reis da Silva destaca que os contatos comerciais "aumentaram”, e concorda com

3 Sobre Cuba deve-se mencionar também a pressão que o governo estadunidense vinha realizando em outros países da região desde a expulsão do país caribenho da OEA. Além disso, o Brasil tinha uma série de compromissos econômicos com credores daquele país que precisavam ser urgentemente equacionados. O gesto político da ruptura com Cuba sublinharia a mudança de comando e o engajamento do novo governo brasileiro em reformas econômicas visando restaurar sua credibilidade no sistema financeiro internacional. 
Vizentini e Cervo que, em relação à URSS, o discurso calcado na Guerra Fria “não correspondeu à prática” (SILVA, 2014, p. 41).

O objetivo deste artigo é, portanto, investigar como essas interações entre os governos do Brasil e da URSS, durante a primeira administração do regime militar, foram importantes para a institucionalização das relações interestatais, visando a retomada das conversações acerca de assistência soviética a grandes projetos de infraestrutura no país. Cervo lembra que foram restabelecidos contatos por delegações bilaterais e reunida, pela primeira vez, a Comissão Mista Bilateral prevista no Acordo de Comércio e Pagamentos de 1963 (CERVO; BUENO, 2008). As delegações brasileiras que estiveram na URSS nesse período buscaram manter vivo o interesse soviético em participar de empreendimentos no ramo energético no Brasil. Em relação ao comércio, no final de 1967, o país retomava o posto de principal parceiro comercial da URSS na América Latina (excetuando-se Cuba).

Para realizar este estudo, concentraremos nossas atenções na análise de fontes primárias. Serão utilizados documentos brasileiros, tanto do Arquivo Histórico do Ministério das Relações Exteriores (AHMRE), em Brasília, como os do acervo do Centro de Pesquisa e Documentação de História Contemporânea do Brasil da Fundação Getúlio Vargas (CPDOC-FGV), no Rio de Janeiro. Além deles, documentos russos obtidos no GARF (Arquivo Estatal da Federação Russa), em Moscou, também serão empregados. Destaco que eventuais erros na tradução desses registros do idioma russo são de minha inteira responsabilidade.

O texto está estruturado em quatro itens. O primeiro apresenta as preocupações anticomunistas do novo governo brasileiro logo após tomar o poder em abril de 1964. Em seguida, trata das iniciativas de reaproximação diplomáticas entre Brasil e URSS iniciadas poucos meses depois. O terceiro analisa, em detalhes, as visitas à URSS das comitivas lideradas por ministros brasileiros em 1965 e 1967. Além disso, comenta a vinda do ministro do Comércio Exterior da URSS ao Brasil em 1966 e outras iniciativas e interações diplomáticas entre os dois países. Por último, expõem-se as conclusões e as perspectivas para as relações bilaterais nos anos subsequentes.

\section{Golpe civil-militar, anticomunismo e relações bilaterais}

Com o golpe civil-militar sendo deflagrado no Brasil em $1^{\circ}$ de abril de 1964 , num cenário doméstico ainda indefinido, o embaixador do Brasil em Moscou, Henrique Rodrigues Valle, enviava uma correspondência detalhada sobre os 
“objetivos econômicos” do governo brasileiro na União Soviética. Dividia-os em três setores: comercial, financeiro e técnico-científico. Valle projetava um comércio bilateral que atingiria US\$500 milhões de parte a parte em 1970. Tal volume possibilitaria "transações financeiras para o desenvolvimento econômico do Brasil". Sobre o terceiro item, o embaixador afirmava que, de acordo com as mesmas projeções, seria possível financiar uma ampla assistência técnica soviética, mas que, na "maioria das vezes", essa estaria vinculada à "aquisição de equipamentos". Por fim, ele solicitava ao Itamaraty mais recursos financeiros e humanos a fim de "concretizar as excelentes promessas econômicas do posto" (AHMRE, 1964a).

Ao mesmo tempo, a radicalização político-ideológica apontava para um desfecho no Brasil. O presidente João Goulart saiu do Rio a Brasília e depois a Porto Alegre numa última tentativa de organizar alguma resistência com o ex-governador Leonel Brizola. No entanto, o presidente do Senado já havia declarado vaga a presidência da República antes mesmo de Goulart exilar-se no Uruguai. O presidente da Câmara dos Deputados, Ranieri Mazzilli, assumia interinamente o cargo. Ao mesmo tempo, uma junta de militares de alta patente das três Armas assumia o poder de facto por duas semanas. Após a decretação do Ato Institucional, o marechal Castello Branco assumia o poder no dia 15 de abril, eleito indiretamente por um Congresso Nacional desfigurado pelo AI-1.

Nesse cenário interno radicalizado pelo anticomunismo, seria natural que os representantes soviéticos no país se inquietassem. Em Moscou, Valle foi convocado para uma reunião pelo ministro interino das Relações Exteriores. A Embaixada da URSS no Rio afirmava em correspondência ao governo soviético que esperava que as autoridades brasileiras agissem de acordo com princípios fundamentais do Direito Internacional, de forma a tomar as providências necessárias para garantir a segurança da Embaixada, bem como de seu pessoal, e dos cidadãos soviéticos que se encontravam no Brasil (AHMRE, 1964b).

Ainda durante o governo provisório de Mazzilli, assumia a chancelaria o ex-embaixador em Moscou e Havana, Vasco Leitão da Cunha. Ele seria mantido após a ascensão de Castello ao poder. Nas semanas seguintes, Cunha confrontar-se-ia com diversas denúncias de espionagem, favorecimento e financiamento de "atividades subversivas" por cidadãos estrangeiros no país. No dia 6 de abril, por exemplo, o embaixador do Brasil no México, Manuel Pio Corrêa Junior, escreveu uma carta pessoal ao chanceler acusando o governo cubano de conceder apoio financeiro a Leonel Brizola e seus apoiadores; afirmando inclusive que a primeira parcela dessas subvenções chegou a ser paga (CPDOC-FGV, 1964a). 
Esse clima de perseguição e anticomunismo minaram as relações diplomáticas entre o Brasil e o bloco soviético durante o primeiro semestre de 1964. Já no início de julho, entretanto, o presidente brasileiro enviou uma mensagem pessoal a Nikita Khrushchev afirmando que o país tinha interesse no incremento comercial com a URSS (VIZENTINI, 1998). Na busca por restaurar alguma confiança, Castello procurava justificar a necessidade da intervenção dos militares na política nacional e, ao mesmo tempo, moderar a maré anticomunista. Para o presidente, as relações com os países do Leste Europeu deveriam ser "mantidas e, em certos terrenos, ampliadas". Segundo ele, o comércio entre o Brasil e os países do bloco soviético poderia ser "mutuamente proveitoso: estamos prontos a aumentar nossas trocas, desde que elas não sejam veículo de influências inaceitáveis" (MRE, 1966 ). Os instrumentos legais necessários para que isso ocorresse na prática já existiam. O Acordo de Comércio e Pagamentos assinado entre os dois países em 1963 - o qual também previa reuniões regulares no âmbito de uma Comissão Mista bilateral - estava em vigência. Desde o reatamento em 1961, as trocas comerciais cresciam de maneira significativa e sempre com saldo positivo para o Brasil - apesar de o volume total ainda ser pequeno quando comparado aos parceiros tradicionais (MILLER, 1989).

\section{Restaurando a confiança pelo comércio}

Ao fazer um balanço dos principais pontos do mês de maio, a Embaixada em Moscou comentava sobre como fora retratada na imprensa soviética a tomada de poder pelos militares no Brasil. Afirmava que, embora considerada pela grande maioria um "golpe reacionário", as críticas eram em "termos ponderados" apesar de "inúmeros exageros e erros de informação" (AHMRE, 1964c).

No início de agosto, o presidente do Conselho do Soviete Supremo, Anastas Mikoyan, acusou o recebimento de carta enviada por Castello Branco. Segundo a Embaixada em Moscou, a comunicação avisava a respeito de o presidente haver "tomado posse no cargo" (AHMRE, 1964d). No final de julho, o Congresso Nacional, por meio da Emenda Constitucional n ${ }^{\circ}$ 9, prorrogava o mandato do presidente até 15 de março de 1967. Havia, portanto, uma indicação ao governo soviético de que o novo governo brasileiro estava se consolidando no poder e que Castello não exerceria apenas um mandato "tampão". 
Algumas semanas depois, o governo brasileiro fazia novo esforço para reforçar às missões diplomáticas do Leste Europeu que a diminuição do comércio com o bloco soviético era algo conjuntural, e não resultado de qualquer tipo de discriminação ideológica. Em comunicação a Moscou, o Itamaraty argumentava que a diminuição havida nas trocas era fruto de "inevitáveis reajustamentos" ocorridos no país após a tomada de poder pelos militares. Dizia ainda que, apesar das dificuldades momentâneas, considerava o quadro de comércio com o Leste Europeu "promissor" (AHMRE, 1964e).

De acordo com Rupprecht (2011) havia um desejo, de ambas as partes, de manter relações diplomáticas amistosas. No começo de setembro, Mikoyan enviou um telegrama a Castello Branco desejando "felicitações" por motivo do aniversário da independência do Brasil. O político soviético expressava a "esperança" de que as relações bilaterais se desenvolvessem no interesse dos povos de ambos os países (AHMRE, 1964f). Da mesma forma, no dia 7 de setembro de 1964, o Izvestia publicou um artigo congratulando o Brasil pelo aniversário de independência e desejando o "fortalecimento de relações amigáveis entre os dois países" (AHMRE, 1964g).

Uma semana depois, o embaixador Valle escreveu uma carta pessoal ao chanceler mostrando-se "muito bem impressionado" com os "inúmeros contatos" que estava mantendo com as autoridades do governo soviético. Disse que manteve conversas com o embaixador da URSS no Brasil, Andrei Fomin - que se encontrava na capital soviética - bem como com funcionários do Departamento de América Latina do Ministério de Negócios Estrangeiros da URSS. Afirmou ainda que teve uma longa entrevista com o ministro do Exterior, Andrei Gromyko, e com seu vice, Vassily Kuznetsov. Notou que todos se mostraram "visivelmente interessados" na manutenção de boas relações bilaterais - inclusive não se limitando apenas a conversas sobre as possibilidades de comércio (CPDOC-FGV, 1964b).

No final de setembro, a Petrobras assinava um compromisso prevendo a "aquisição adicional" de 2 milhões de toneladas de petróleo da URSS para o ano seguinte (AHMRE, 1964h). Descontada certa dose de cortesia diplomática recíproca, as relações bilaterais estavam ganhando importância de fato - mais pelas perspectivas futuras do que pelos dados presentes.

A mudança de tom também estava relacionada com a troca de comando em curso na URSS. Em 14 de outubro de 1964, o Comitê Central do PCUS confirmou o afastamento de Khrushchev, e a nomeação do novo líder, Leonid Brejnev, encerrando uma conspiração interna que estava em marcha desde março. Duras acusações de quadros importantes do Partido sobre a política doméstica de Khrushchev, bem 
como decisões precipitadas no campo externo, selaram sua retirada do posto. Brejnev não possuía experiência alguma em assuntos de política exterior. Além da importante influência de Gromyko, deve-se pesar também, principalmente no início de sua administração, a proeminência do primeiro-ministro Alexei Kosygin nos assuntos externos do país - inclusive representando a URSS em diversos encontros com líderes estrangeiros (SAVRANSKAYA; TAUBMAN, 2011).

Ao mesmo tempo, o ano de 1964 foi marcado pelo início de uma aproximação política, econômica e cultural entre EUA e URSS. Um grupo de mais de 90 empresários estadunidenses de alto perfil foi a Moscou em novembro a fim de verificar as possibilidades de expansão das relações econômico-comerciais entre os dois países (AHMRE, 1964i). A comitiva estadunidense foi recebida pela alta cúpula do PCUS. De Moscou, Valle falava em uma "radical mudança na filosofia e na pragmática socialista”. A longo prazo, afirmava que a mudança poderia ser ainda "mais radical” em comparação aos parâmetros que regiam as relações entre os mundos capitalista e socialista (AHMRE, 1964i).

\section{Preparando o terreno para novas parcerias}

No início de abril de 1965, o embaixador Valle esteve com o premiê Kosygin. Este, segundo o diplomata brasileiro, enfatizou a importância do desenvolvimento das relações bilaterais em "todos os setores” e que não haveria "limites à melhoria das relações entre os dois países”. Assinalou o "substancial progresso” no intercâmbio comercial - mesmo afirmando em seguida que as relações econômicas ainda estariam “bastante aquém” das “possibilidades reais”. Voltou a dizer que a URSS tinha "grande interesse" no aumento das trocas comerciais com o Brasil e solicitou que suas opiniões fossem transmitidas diretamente ao presidente Castello Branco (AHMRE, 1965a).

Estavam firmadas as bases, portanto, para um encontro de alto nível. Isso se concretizaria em setembro com uma visita do civil mais influente do governo à URSS, o ministro do Planejamento Roberto Campos. Antes de sua partida, no entanto, o chefe de gabinete do chanceler Cunha, Mozart Gurgel Valente, enviou algumas "respostas aconselháveis" a três perguntas que considerava "previsíveis" dos interlocutores soviéticos. A primeira era uma negação à possibilidade de instalação de um Consulado da URSS em São Paulo. De acordo com Valente, o governo brasileiro não via "utilidade prática”, mas se houvesse “incremento do 
comércio" poderia reavaliar o assunto. O segundo ponto dizia respeito à instalação de um Escritório Comercial da URSS em São Paulo. Esse estaria autorizado desde que "a conclusão de um acordo de cooperação econômica" viesse a "criar a expectativa de um incremento do intercâmbio". O último dizia respeito à aquisição de uma casa pelo governo soviético para ser a nova sede da representação soviética no Rio de Janeiro. O governo brasileiro afirmava aguardar a "conclusão dos estudos jurídicos” para se manifestar sobre o assunto. (AHMRE, 1965b). Nas três respostas, o mesmo dilema para a administração brasileira: os possíveis ganhos no campo econômico-comercial compensariam potenciais ameaças à segurança nacional?

Ainda antes da viagem, em agosto, uma reunião no âmbito do Conselho de Segurança Nacional foi convocada para discutir aspectos gerais da viagem do ministro à União Soviética. Nesse encontro, o próprio Campos colocou-se favoravelmente à possibilidade de financiamento soviético a obras de infraestrutura no país; citou particularmente uma planta piloto de xisto betuminoso e o projeto da usina hidrelétrica de Ilha Solteira no Estado de São Paulo. Apesar de o presidente também ser favorável, a maioria dos integrantes do CSN se mostrou contrária a essa empreitada - principalmente a cúpula militar. As razões eram conhecidas: possibilidade de infiltração comunista e/ou deterioração das relações com o governo estadunidense (CSN, 1965).

Mesmo assim, durante a primeira quinzena de setembro de 1965, uma comitiva liderada por Campos esteve por 12 dias na URSS. A delegação esteve em Moscou, Leningrado (São Petersburgo), Volgogrado (ex-Stalingrado), Tallinn e Bratsk - cidade siberiana que abrigava a então maior usina hidrelétrica do mundo. Na Estônia, o interesse estava na visita a uma planta de exploração de xisto betuminoso; já em Volgogrado, em conhecer uma grande siderúrgica e outra importante usina hidrelétrica no rio Volga (CAMPOS, 2004).

O ministro propunha que a melhor maneira de assegurar uma "corrente de exportação de equipamentos" seria que a União Soviética financiasse a execução de projetos. Entretanto, apresentava, da mesma forma, dificuldades a serem equacionadas, se o governo soviético desejasse operar esses financiamentos de cooperação econômica como havia feito, por exemplo, nos casos do Egito e da Índia (AHMRE, 1966m). Isso porque, segundo Campos, havia empreiteiros brasileiros capacitados, alguns até com capacidade ociosa em maquinaria, para a realização desse tipo de projeto. Assim, seria impossível entregar aos soviéticos a "responsabilidade total" dessas empreitadas. Pelo mesmo motivo, a assistência técnica necessária poderia ser mais limitada (AHMRE, 1965c). 
O governo brasileiro dava preferência a ter um "crédito global" junto ao governo soviético que seria empregado em projetos analisados posteriormente no âmbito da Comissão Mista bilateral; evitando um compromisso imediato por parte da comitiva brasileira com uma "lista de projetos" já previamente elaborada por sua contraparte soviética (AHMRE, 1965c).

De acordo com o ministro, a reação dos representantes comunistas foi "bastante negativa". Queixaram-se de que havia realmente "grande interesse” em alguns projetos, mas mostraram decepção em relação à falta de uma disposição clara por parte do governo brasileiro em indicá-los. Relembraram tentativas anteriores infrutíferas causadas por imaturidade do projeto ou oposição governamental (AHMRE, 1965c). Referiam-se ao contrato assinado em 1960 entre a organização de comércio exterior soviética Tiajpromexport e a empresa brasileira Companhia Industrial de Rochas Betuminosas (CIRB) (AHMRE, 1965d) para a exploração do xisto, e conversações a respeito de Sete Quedas (AHMRE, 1964j).

Ainda segundo Campos, o governo soviético tinha "enorme interesse" em prestar assistência técnica ao Brasil e em iniciar conversações imediatamente sobre projetos específicos de interesse comum. Nutriam simpatia, por exemplo, pelo projeto da usina de Ilha Solteira, em SP, estimando-o em cerca de US\$ 160 milhões - entre matérias-primas e maquinaria importada. No entanto, para o Brasil, de acordo com o ministro, o adiamento de indicações sobre projetos específicos poderia ser benéfico: daria tempo para o Conselho de Segurança Nacional deliberar sobre a questão do xisto betuminoso (AHMRE, 1966a) e proporcionaria uma melhor certificação das condições técnicas (visitas a usinas hidrelétricas e fábricas de equipamento soviéticas) por parte do responsável do lado brasileiro (AHMRE, 1965c).

Dessa forma, a viagem de Campos serviu para abrir as "portas para a cooperação econômica com o campo soviético”, já que, dois meses depois, o ministro-conselheiro Nogueira Porto iria a Moscou para a Reunião da Comissão Mista prometendo envolver os empresários paulistas nas trocas comerciais com a URSS (VIZENTINI, 1998, p. 63-64). Poucas semanas antes da chegada de Campos a Moscou, Valle, em reunião com Kuznetsov, já havia afirmado que representantes de muitas empresas brasileiras estavam interessados em visitar a URSS, num futuro próximo, a fim de estabelecer contato com suas organizações comerciais (GARF, 1965).

O pragmatismo soviético nas relações com o Brasil era fruto de mudanças importantes que estavam ocorrendo na URSS. De Moscou, Valle, em comunicação 
ao Itamaraty, usava como exemplo a atuação de Kosygin, agindo pela construção da paz entre Índia e Paquistão nas reuniões de Tashkent, como exemplo de uma "convencionalização" da diplomacia soviética. O argumento era o seguinte: embora não abandonasse sua antiga pretensão de liderar o movimento comunista internacional, a URSS teria de se preocupar mais com suas questões internas; principalmente com relação às expectativas de melhoria da condição de vida da maior parte de sua população. Tal anseio seria "bem mais forte" do que o ardor revolucionário das gerações que fizeram a Revolução de 1917 e lutaram contra a Alemanha nazista (AHMRE, 1966b).

Havia, de fato, mudanças importantes em andamento na economia e na política externa soviéticas. Do ponto de vista comercial, houve uma reorientação geográfica dos fluxos. Em 1958, a URSS comerciava com 70 países, dos quais 50 por meio de acordos bilaterais. No fim de 1964, esses números elevaram-se respectivamente para 100 e 70. No período 1958-64, o comércio da URSS com os países de seu bloco cresceu $68 \%$. Já com os países desenvolvidos capitalistas, o aumento foi de $126 \%$. O número de países em desenvolvimento com os quais a URSS mantinha acordos de comércio e pagamentos passou de 17, em 1958, para 40, em 1964 (AHMRE, 1966c).

Obviamente, um aumento do comércio bilateral interessava ao Brasil. O especialista em assuntos econômicos da Embaixada em Moscou considerava o mercado soviético "bastante promissor" para alguns produtos brasileiros (AHMRE, 1966d). O encarregado de negócios afirmava que a possibilidade de assinatura de um protocolo para a venda financiada de máquinas e equipamentos soviéticos ao Brasil oferecia uma oportunidade "afresh" para pensar as possibilidades do comércio bilateral (AHMRE, 1966e e 1966f). Poucos dias depois, sugestões de modificações a uma segunda proposta soviética foram feitas por um grupo integrado por representantes ministeriais e de autarquias do governo brasileiro (AHMRE, 1966g).

Com "a expectativa de um incremento do intercâmbio" realizada - lembrando a condição estabelecida pelo chefe de gabinete do chanceler em correspondência a Campos antes de sua viagem à URSS - , havia chegado o momento de analisar seriamente a proposta soviética de instalar "agências comerciais soviéticas" não somente em São Paulo, mas também no Rio de Janeiro - mediante reciprocidade (AHMRE, 1966h).

De acordo com comunicação da Secretaria Geral Adjunta para Assuntos de Europa Oriental e Ásia, o novo chefe de gabinete do chanceler, Pio Corrêa, 
comunicou-se com o chefe do SNI, Golbery do Couto e Silva, a respeito disso em julho de 1966. Afirmava que o Itamaraty pretendia autorizar a abertura das representações, pois a equipe econômica do governo, ministro Campos "à frente", insistiram sobre a necessidade de os soviéticos agirem "junto ao setor privado brasileiro no sentido de estimular sua capacidade de importação de produtos da área socialista" (AHMRE, 1966h). Pio Corrêa também se comunicou diretamente com a mesma Secretaria, afirmando seu desejo de se ter apenas dois cidadãos soviéticos trabalhando em cada representação. Em resposta, Meira Penna temia que tal medida pudesse desinteressar as autoridades soviéticas pela assinatura de um protocolo para máquinas e equipamentos, e que isso implicasse no "cancelamento da própria viagem" do ministro do Comércio Exterior, Nikolai Patolichev, ao Brasil - marcada para o mês seguinte. Ele fazia questão de lembrar que estava "em jogo" um "financiamento da ordem de US\$ 100 milhões" e, em "última análise, todo o futuro de nossas relações comerciais com a URSS" (AHMRE, 1966i, 1966j e 1966k).

Em agosto de 1966, o Itamaraty enviou uma nota à Embaixada soviética concordando com a instalação da Seção de Representação Comercial em São Paulo (AHMRE, 1966h). A decisão havia sido tomada provavelmente no final de julho ou início de agosto. Com as exigências de segurança atendidas, o Escritório Comercial da URSS seria finalmente aberto em janeiro de 1967, proporcionando um acesso "direto" ao mercado paulista (AHMRE, 1966h).

Também em agosto, Patolichev chegava ao país para assinar o Protocolo para Fornecimento de Máquinas e Equipamentos. Nele, o governo soviético concedia um crédito de US\$ 100 milhões ao Brasil para o período 1966-69. No entanto, mesmo com tal incentivo, apesar de grandes flutuações anuais, o petróleo chegou a responder por $90 \%$ do valor exportado da URSS ao Brasil; e liderava isolado como principal produto soviético enviado ao país em 1966 (BLASIER, 1989). As condições de pagamento eram atraentes. Previam juros de $4 \%$ e um prazo de carência de dois a oito anos de amortização, após a entrega dos equipamentos. Três meses depois, uma delegação de burocratas brasileiros esteve em Moscou para discutir o conteúdo de listas de mercadorias entre Brasil e URSS para o triênio 1965-68, além das modalidades de financiamento em cruzeiros às pequenas e médias indústrias (VIZENTINI, 1998).

Após essa aproximação concreta, uma proposta de cooperação científica seria cogitada por parte do Brasil. Em uma conversa com o vice-diretor do Departamento de Américas do Ministério dos Negócios Estrangeiros, Valle considerava possível 
a assinatura de um acordo bilateral no campo da astronomia. Baseando-se em um entendimento já existente entre URSS e Chile, o embaixador comentava a assistência técnica fornecida ao país andino. Segundo ele, uma iniciativa desse tipo com o Brasil seria "útil para ambas as partes" (GARF, 1966a). Pelo lado da superpotência, a Academia de Ciências da URSS mostrou-se imediatamente interessada e pronta para iniciar negociações visando um acordo de cooperação científica para pesquisa astronômica com auxílio de satélites artificiais; o assunto reapareceria posteriormente (GARF, 1966b) (AHMRE, 1969). No ano seguinte, Valle - em conversa com um diplomata soviético - reafirmou o interesse do governo brasileiro e de cientistas do país em estabelecer um intercâmbio regular de informações técnicas e científicas com a URSS (GARF, 1967).

Esse tipo de aproximação tinha se tornado possível porque uma atmosfera de distensão entre as duas superpotências estava emergindo. Quando o ministro da Indústria e Comércio do Brasil, Paulo Egydio Martins, chegou em Moscou chefiando uma missão comercial, em janeiro de 1967, foi avisado da disposição do embaixador dos EUA na capital soviética em encontrá-lo. De acordo com as memórias do ministro, Llewellyn Thompson foi vê-lo na Embaixada dizendo que achava "fundamental estabelecer um entendimento maior com a União Soviética através do comércio" (MARTINS, 2007, p. 300). Também na Embaixada, Valle ofereceu um almoço que contou com a presença de diversos embaixadores latino-americanos creditados em Moscou (AHMRE, 1967a). A comitiva brasileira incluía 30 grandes empresários brasileiros (MARTINS, 2007).

Em Moscou, o grupo esteve com o ministro Patolichev e com o presidente do Presidium, Nikolai Podgorny, numa reunião que integrava os empresários brasileiros e os diversos representantes das organizações de comércio exterior soviéticas. De acordo com Martins, por iniciativa dele, foi alocada uma cota de açúcar brasileiro nas importações soviéticas - já que a URSS adquiria o produto majoritariamente de Cuba. Além disso, o café solúvel estava com vendas crescentes na URSS; fato que estimulou a ida da missão (MARTINS, 2007).

Havia uma perspectiva de aplicação imediata do Protocolo Patolichev por meio de um projeto para construção de uma fábrica petroquímica no Brasil. O valor do projeto era de US\$ 5 milhões, o que permitiu ainda a exportação de manufaturas brasileiras à URSS no valor de US\$ 1,25 milhão (AHMRE, 1967b).

Ao final de 1967, o Brasil já retomava o posto de maior parceiro comercial da URSS na América Latina (excetuando-se Cuba). No entanto, o volume das trocas era menor do que em 1962-1963. Um aumento expressivo das 
exportações à URSS se daria somente em 1972 (MILLER, 1989) no auge do chamado “milagre econômico”. No entanto, os créditos soviéticos utilizados totalizavam apenas US\$ 4 milhões em 1969, e US\$ 6 milhões em 1971 (MILLER, 1989) (PRIZEL, 1990).

Mesmo assim, ainda no final de 1969, o Protocolo sobre Fornecimento de Maquinaria e Equipamentos da URSS ao Brasil seria assinado - substituindo o Protocolo Patolichev - no valor de US\$ 100 milhões para o período de 1970-74. (VIZENTINI, 1998). Finalmente, em 1970, acordos entre a Energomashexport e CESP (Centrais Elétricas São Paulo) seriam concluídos. O entendimento tratava do fornecimento de equipamentos e turbinas para a usina hidrelétrica de Capivara, na divisa entre SP e PR (VIZENTINI, 1998). Elas se tornariam, em 1977, as primeiras turbinas hidroelétricas soviéticas em operação na América Latina (MILLER, 1989). Dois anos depois, a usina hidrelétrica de Sobradinho (BA) também entraria em operação utilizando turbinas soviéticas. O acordo para o fornecimento dos equipamentos havia sido assinado em 1975 (PRIZEL, 1990) (BLASIER, 1989). Eram projetos de grande porte e de importância estratégica para o desenvolvimento do Brasil.

Apesar de mostrar-se interessada por Sete Quedas desde os primórdios do projeto, os soviéticos não conseguiriam participar do fornecimento de máquinas para esse enorme empreendimento. O interesse soviético no setor energético brasileiro reapareceria renovado, numa conjuntura de aproximação entre os dois países, no início do governo Figueiredo (1979-1985).

\section{Conclusão}

Após a ruptura de 1964, a equipe econômica de Castello Branco considerava importante ampliar as trocas com o bloco soviético. Esses contatos possibilitaram uma maior institucionalização das relações bilaterais, uma reativação das conversações acerca de financiamentos, programas de assistência técnica e cooperação econômica entre os dois países.

O aprofundamento das relações econômicas, no entanto, esbarrava nas preocupações brasileiras com segurança interna. O aumento de representações soviéticas no Brasil ensejava um debate dentro do governo brasileiro sobre a conveniência ou não de uma maior presença da URSS no país. Essa questão permaneceu como fonte de discórdia até o fim do regime militar em 1985. 
No entanto, conforme mencionamos, mesmo com a ruptura de 1964, a manutenção das relações bilaterais ocorreu devido a três fatores: o fato de o anticomunismo da cúpula militar brasileira estar concentrado em Cuba e não na URSS, mudanças domésticas importantes em curso na superpotência socialista e a possibilidade de a mesma exercer um papel importante na industrialização do Brasil.

Além disso, as relações com a União Soviética poderiam servir como uma espécie de barganha em relação a eventuais ruídos nas interações do Brasil com os Estados Unidos. É interessante notar que a aproximação do Brasil aos EUA durante o governo Castello Branco não correspondeu a um afastamento da URSS.

Assim, percebe-se que havia aspectos da détente entre as duas superpotências já em 1964. Foi nessa conjuntura que se iniciaram os esforços para uma reaproximação entre Brasil e URSS. A viagem de Roberto Campos, o entendimento a respeito da exploração de xisto, a assinatura do Protocolo Patolichev, a missão chefiada por Paulo Egydio, a construção da planta petroquímica na Bahia, o início das conversações a respeito da cooperação técnico-científica no campo da astronomia e a abertura do Escritório Comercial da URSS em São Paulo atestam esse objetivo. O gradual incremento comercial, a ativação da Comissão Mista Bilateral e, mais tarde, a assinatura do Protocolo de Maquinaria e Equipamentos assegurariam a confiança e a estrutura legal necessárias para que projetos de cooperação econômica bilateral ocorressem na década seguinte.

\section{Referências bibliográficas}

BARRETO FILHO, Fernando Paulo M. Os Sucessores do Barão: relações exteriores do Brasil, v. 2, 1964-1985. São Paulo: Paz e Terra, 2006.

BLASIER, Cole. The giant's rival: the USSR and Latin America, Revised Ed. Pittsburgh: University of Pittsburgh Press, 1989.

CAMPOS, Roberto. A Lanterna na Popa: memórias, $4^{\mathrm{a}}$ ed., $1^{\mathrm{a}}$ reimpressão. Rio de Janeiro: Topbooks, 2004.

CERVO, Amado L.; BUENO, Clodoaldo. História da política exterior do Brasil, $3^{\mathrm{a}}$ ed. Brasília: Editora Universidade de Brasília, 2008.

MARTINS, Paulo Egydio. Paulo Egydio Conta: depoimento ao CPDOC/FGV. Organização Verena Alberti, Ignez Cordeiro de Farias, Dora Rocha. São Paulo: Imprensa Oficial do Estado, 2007. 
MILLER, Nicola. Soviet relations with Latin America, 1959-1987. Cambridge: Cambridge University Press, 1989 (2009).

MRE, MINISTÉRIO DAS RELAÇÕES EXTERIORES. A Política Exterior da Revolução Brasileira. Seção de Publicações, "Discurso por ocasião da entrega de diplomas aos candidatos aprovados por concurso à carreira de diplomata”, 31 de julho de 1964, Departamento de Imprensa Nacional, Setor de Publicações, 1966.

PRIZEL, Ilya. Latin America through Soviet eyes: the evolution of Soviet perceptions during the Brezhnev era, 1964-82. Cambridge: Cambridge University Press, 1990 (2008).

RUPPRECHT, Tobias. Socialist high modernity and global stagnation: a shared history of Brazil and the Soviet Union during the Cold War. Journal of Global History, Vol. 6, No. 3, Novembro 2011 p. 505-528.

SAVRANSKAYA, Svetlana; TAUBMAN, William. Soviet Foreign Policy, 1962-1975 in The Cambridge History of the Cold War, Volume II, Crises and Détente, editado por Melvyn P. Leffler and Odd Arne Westad. Cambridge, Cambridge University Press, 2011, no. 7, p. 134-157.

SILVA, André Luiz R. Interdependência, Segurança e Desenvolvimento: a Política Externa do Governo Castello Branco In SILVA, André Luiz R.; SVARTMAN, Eduardo M. (coords.). Política externa brasileira durante o regime militar (1964-1985). Curitiba: Juruá, 2014.

VIZENTINI, Paulo F. A política externa do regime militar brasileiro: multilateralização, desenvolvimento e a construção de uma potência média (1964-1985). Porto Alegre: Ed. Da Universidade/UFRGS, 1998.

VOLCHEK, Boris. URSS-Brasil: 40 anos de relações diplomáticas in Brasil-URSS: 40 anos do estabelecimento de relações diplomáticas. Rio de Janeiro: Revan, 1985.

Referências documentais

AHMRE, 1964a, AHMRE, Moscou, 2305, “Instalação do SEPRO em Moscou”. Moscou, $1^{\circ}$ abril 1964.

AHMRE, 1964b, AHMRE, Moscou, 2342, "Pedido do Chanceler soviético para garantir a Embaixada soviética e seu pessoal”. Moscou, 4 abril 1964.

AHMRE, 1964c, AHMRE, Moscou, 2306, Moscou-MRE, "Relatório Mensal n 5. Maio de 1964”, Moscou, 10 junho 1964, Anexo, p. 1.

AHMRE, 1964d, AHMRE, Moscou, 2306, Moscou-MRE, "Carta de Chancelaria acusando recebimento de comunicação da posse do Presidente da República”, Moscou, 7 agosto 1964.

AHMRE, 1964e, AHMRE, 811 (42) (70), Confidencial, MRE-Moscou, "Intercâmbio comercial do Brasil com o Leste Europeu”, Rio, 24 agosto 1964, p. 2-3.

AHMRE, 1964f, AHMRE, Moscou, 2306, Moscou-MRE, "Remessa de notícias do Brasil e respectivas traduções”, Moscou, $1^{\circ}$ outubro 1964. 
AHMRE, 1964g, AHMRE, Moscou, 2306, Moscou-MRE, "Relatório de notícias sobre o Brasil e respectivas traduções”, Moscou, 15 setembro 1964, Anexo, p. 1.

AHMRE, 1964h, AHMRE, Moscou, 2351, MRE-Moscou, "Compra adicional de petróleo na URSS”, Rio, 30 setembro 1964.

AHMRE, 1964i, AHMRE, Moscou, 2358, Moscou-MRE, “Colaboração econômica entre a indústria americana e a União Soviética”, Moscou, 18 novembro 1964, p. 1-2.

AHMRE, 1964j, AHMRE, Moscou, 2342, "Visita de despedida do Embaixador brasileiro a Brejnev e Gromiko”. Moscou, 9 fevereiro 1964, p. 1.

AHMRE, 1965a, AHMRE, 920 (42) (74) (1965-66), MRE-Gabinete em Brasília, Confidencial, "Relações soviético-brasileiras”, 6 abril 1965.

AHMRE, 1965b, AHMRE, 920 (42) (74) (1965-66), Mozart Gurgel Valente para Roberto Campos, Confidencial, Rio, 30 agosto 1965.

AHMRE, 1965c, AHMRE, 812 (42) (74), Moscou ao MRE, Confidencial, "Viagem do Ministro Roberto Campos à Rússia”, 8 setembro 1965, p. 2.

AHMRE, 1965d, AHMRE, 812 (42) (74), MRE a Moscou, Confidencial, "Visita do Ministro do Planejamento à URSS”, 10 junho 1965.

AHMRE, 1966a, AHMRE, Moscou, 2310, Moscou-MRE, “Brasileiros em Moscou em 1965”, Moscou, 19 janeiro 1966, p. 3-4.

AHMRE, 1966b, AHMRE, Moscou, 2310, Moscou-MRE, “Transformações na diplomacia soviética. Opiniões americanas”, Moscou, 24 fevereiro 1966, p. 3 e 6.

AHMRE, 1966c, AHMRE, Moscou, 2310, Moscou-MRE, "Comércio exterior soviético em 1964”, Moscou, 19 janeiro 1966, p. 2.

AHMRE, 1966d, AHMRE, Moscou, 2312, Moscou-MRE, "Mercado Soviético para uma Lista Selecionada de Produtos de Exportação Brasileira”. Moscou, julho de 1966, p. 14-15. AHMRE, 1966e, AHMRE, Moscou, 2312, Moscou-MRE, "Acordo comercial Brasil-URSS. Mercado soviético para uma lista selecionada de produtos brasileiros”, Moscou, 12 julho 1966, p. 2-3. Veja também

AHMRE, 1966f, AHMRE, Moscou, 2312, Moscou-MRE, "Projeto soviético de Protocolo sobre vendas financiadas de máquinas e equipamentos. Importações soviéticas de bens industriais”, Moscou, 15 julho 1966.

AHMRE, 1966g, AHMRE, 812 (42) (74), MRE-Moscou, Confidencial, "Protocolo sobre vendas financiadas de máquinas e equipamentos pela URSS ao Brasil”, Rio, 14 julho 1966.

AHMRE, 1966h, AHMRE, 921 (74) (00), Confidencial, Secretaria Geral Adj. para Assuntos de Europa Oriental e Ásia ao Ministro de Estado, "Escritório Comercial da URSS em São Paulo”, Rio, 3 agosto 1966, p. 1.

AHMRE, 1966i, AHMRE, 812 (74) (00), Confidencial, Secretaria de Estado para Secretário Geral Adjunto para Assuntos da AEAs, Rio de Janeiro, 12 julho 1966 e, logo em seguida, 
AHMRE, 1966j, AHMRE, 812 (74) (00), Confidencial José Oswaldo de Meira Penna ao Secretário Geral, 19 julho 1966.

AHMRE, 1966k, AHMRE, 812 (74) (00), Confidencial, Paulo Leão de Moura ao Secretário Geral, 23 julho 1966.

AHMRE, 1966l, AHMRE, 921 (74) (00), Confidencial, Secretaria Geral Adjunta para Assuntos de Europa Oriental e Ásia ao Ministro de Estado, "Escritório Comercial da URSS em São Paulo”, Rio de Janeiro, 3 agosto 1966, p. 2.

AHMRE, 1966m, AHMRE, Moscou, 2312, "Feiras e Exposições. Participação soviética”, Moscou, 25 agosto 1966.

AHMRE, 1967a, 812 (42) (74), Moscou-MRE, Confidencial, "Viagem do Ministro Paulo Egydio aos países da Europa Oriental”, Moscou, 23 janeiro 1967.

AHMRE, 1967b, AHMRE, Moscou, 2315, Moscou-MRE, "Protocolo de Cooperação econômica e técnica entre o Brasil e a URSS”, Moscou, 23 janeiro 1967, p. 2.

AHMRE, 1969, AHMRE, 921.1 (42) (74), Secreto, MRE-Moscou, "Instruções para o Embaixador brasileiro em Moscou”, Rio, 24 janeiro 1969, p. 9-10.

CPDOC-FGV, 1964a, VLC e 1964.03.10, IX, p. 1-2, "Pio Corrêa para Vasco Leitão da Cunha”, México, 6 abril 1964.

CPDOC-FGV, 1964b, VLC e 1964.03.10, XIX, Henrique Rodrigues Valle para Vasco Leitão da Cunha. Moscou, 14 setembro 1964, p. 1.

CSN, Conselho de Segurança Nacional, Ata da Vigésima Oitava Reunião do Conselho de Segurança Nacional, Livro de Atas nº 2, p. 241-283 em < http://memorialanistia. org.br/conselho-de-seguranca-nacional-atas/ > .

GARF, 1965, f. 9518, op. 1, d. 324, 9 agosto 1965, p. 194.

GARF, 1966a, f. 9518, op. 1, d. 997, 27 setembro 1966, p. 112.

GARF, 1966b, f. 9518, op. 1, d. 997, $1^{\circ}$ novembro 1966, p. 121.

GARF, 1967, f. 9518, op. 1, d. 998, 10 de abril de 1967, p. 21. 